inil

waim
RAXIMHAI ISSN-1665-0441

Volumen 9 NÚMERo 2 JULIO-DICIEMBRE 2013

105-129

\title{
LOS CAMINOS PARA LA PAZ EN COLOMBIA
}

\section{WAYS FOR PEACE IN COLOMBIA}

Eduardo Andrés Sandoval Forero

\section{Resumen}

El presente texto trata sobre el conflicto sociopolítico y la violencia directa, estructural y cultural que viene presentándose en Colombia desde la década de los años cincuenta del siglo pasado. A partir de los estudios para la paz y los conflictos, se reflexiona acerca de la confrontación armada, sobre las diferentes perspectivas de la negociación entre el gobierno y la insurgencia, y sobre la construcción de la paz. Se exponen algunas ideas significativas de organización de la sociedad civil en torno a los procesos de paz, y se elaboran algunas reflexiones en torno a los posibles escenarios de la paz negativa, positiva, imperfecta e integral con justicia, libertad y democracia.

Palabras clave: Violencia estructural, violencia cultural, violencia directa, tipos de paz

\section{Abstract}

This paper addresses the socio-political conflict and direct violence, structural and cultural performing in Colombia comes from the decade of the fifties of last century. From the peace studies and conflict, reflects on the armed confrontation of different perspectives of negotiation between the government and the insurgency, and peace building. Are some significant ideas of civil society organizations around the peace process, and made some reflections on the possible scenarios of negative peace, positive and integral with imperfect justice, freedom and democracy.

KeyWords: Structural violence, cultural violence, direct violence, types of peace 


\section{INTRODUCCIÓN}

Colombia es un país ubicado en el sur de América, con importantes extensiones marítimas en el océano Pacífico y Atlántico, con alrededor de 47 millones de habitantes, y de acuerdo al Departamento Administrativo Nacional de Estadísticas (DANE 2005) con datos del censo 2005, extrapolados al 2010, cerca de cinco millones viven fuera del país. Posee una gran diversidad biológica, étnica y cultural (mestizos, indígenas, afrocolombianos, gitanos, creoles). Formalmente el sistema político colombiano está integrado por tres ramas de poder: el ejecutivo, el legislativo y el judicial. Mediante elecciones se elige presidente de la república, así como a los miembros de las corporaciones públicas. La existencia de diferentes partidos y organizaciones de oposición forman parte del contexto político, que suele denominarse explícitamente un sistema democrático.

Colombia registra una larga historia de gobiernos civiles emparentados con todo un proceso de períodos tanto selectivos como generalizados de violencia política, social, cultural, armada- y económica. La historia del país también ha estado marcada por intensos procesos de construcción de paz que han sido organizados y cimentados por organizaciones civiles, sindicatos, gremios, universidades, mujeres, campesinos, indígenas, comunidades de afrocolombianos, organizaciones no gubernamentales, iglesias e instituciones del gobierno. Incluso varios de los actores armados han sido recurrentes en los discursos de la paz y han "justificado" sus organizaciones, sus políticas, y su accionar armado en la búsqueda de la justicia y la paz social.

Pero la violencia y los conflictos en Colombia no han sido ni son exclusivamente armados, de confrontación militar directa. Sin duda son altamente destructores de vida, de familias, de sociedad, de cultura y de país, por lo que sus irracionales y absurdas lógicas y prácticas violentas transgreden cualquier condición humana más elemental de la tierra. Ellos son los paramilitares o para-estado, las guerrillas de todas las tendencias políticas, los narcotraficantes, la delincuencia común, el ejército nacional, y la combinación indistinta entre ellos.

Existen otras violencias, otros conflictos y construcciones de paz, que poco suelen ser abordadas en los estudios académicos y políticos, entre otras razones por nuestra dominante visión violentológica de la realidad, de la historia y del presente. La estructura socioeconómica violenta del estado; las violencias simbólicas y reales contra los indígenas, los afros, los campesinos, los gitanos y el género femenino; la violencia intrafamiliar; la trata de mujeres 
para la prostitución; la expoliación de territorios ocupados por campesinos e indígenas para la extracción minera; la expropiación de tierras de campesinos e indígenas por parte del Estado y de terratenientes; la exponencial corrupción de funcionarios públicos y la impunidad; la deforestación y la privatización creciente de las riquezas hídricas nacionales; la violación a los derechos humanos; la marginación y la exclusión laboral, educativa y de género; y la violencia contra la naturaleza, son, entre muchas otras, dinámicas que suelen ser no consideras en esa dimensión de las violencias.

Todos estos sufrimientos que acompañan a la población en general, son propios de un sistema económico capitalista que en su política neoliberal ha impuesto a los mercados nacionales e internacionales por encima de las necesidades humanas de la mayoría de la población. Es decir, que el capitalismo neoliberal en tiempos de la globalización ha incrementado en todas sus dimensiones las violencias, los conflictos, y la injustica social, incluyendo el sometimiento del Estado al mercado capitalista. Estas violencias tienen su expresión en la distribución desigual de la riqueza, que no es más que la injusticia estructural de derechos básicos económicos, sociales y culturales de la población, que hacen que el vivir en paz se encuentre en condiciones de una imperfección cada vez más lamentables.

Así es como la historia de los colombianos está marcada por palabras muy significativas como: represión, subversión, violencias, conflictos, movilizaciones, desplazamiento, exilio, negociaciones, diálogos y paz. Esto quiere decir que los pensamientos y las prácticas tanto del Estado como de la población colombiana, han estado en dinámicas constructoras de paz en condiciones de imperfección, toda vez que de manera constante las variables de las violencias hacen presencia y alteran el sendero para accesar a una paz duradera con base en la justicia social, la libertad y la democracia. Esta paz alude al pensamiento y a la construcción de convivencias pacíficas en contextos latinoamericanos, lo que implica otros senderos para la paz, las del Sur, que difieren de la paz colonial y neoliberal del pensamiento único occidental europeo, que, entre otras, condiciona en el "desarrollo" la construcción de la paz. El mismo "desarrollo" que ha venido siendo impulsado y recetado para los países del Sur después de la segunda guerra mundial, el cual ha consistido en la expoliación de los recursos naturales, la destrucción del medio ambiente, el enriquecimiento de trasnacionales y élites económicas nacionales así como el empobrecimiento de la mayoría de la población.

A partir del brevísimo contexto anotado, pretendemos en el presente ensayo 
abordar la problemática referida al conflicto armado en Colombia desde las perspectivas de los estudios para la paz, lo cual implica entender el conflicto violento a partir de las dimensiones conceptuales que aluden a las condiciones estructurales, económicas, sociales, culturales y políticas en el país. Iniciamos con un micro resumen del conflicto sociopolítico para que los no colombianos tengamos un referente comprensivo de aproximación contextual al fenómeno, mismo que pretendemos no solo plasmar desde lo que se puede denominar una visión violentológica, sino también desde una mirada de paz (no pazologa) que permita dimensionar las violencias existentes y también la subjetividades y realidades constructoras de paz. Se trata que la perspectiva de la violencia no excluya las realidades de paz, pero tampoco que las miradas de la paz no nieguen ni invisibilicen las violencias.

\section{EL CONFLICTO SOCIOPOLÍTICO}

En este apartado asumimos que el conflicto armado en Colombia es producto de la relevancia que tienen las violencias en el país, las cuales son mantenidas por la política dominante del Estado y de los gobiernos que han estado presentes en la historia nacional. Además de ello, también es producto del proyecto de las organizaciones político militares genéricamente de izquierda, que han tenido como principio "la toma del poder" a través de la "lucha armada".

Pero en el caso que nos atañe, además del Estado y las guerrillas, aparecen en el escenario de la guerra otros actores violentos como los grupos paramilitares, grupos de narcotraficantes y grupos armados de delincuencia común. Es por ello que el concepto general de Fisas (2004) puede ser útil para la conceptualización de este complejo fenómeno:

Entendemos por conflicto armado todo enfrentamiento protagonizado por grupos de diversa índole, tales como fuerzas militares, regulares o irregulares, grupos armados de oposición, grupos paramilitares o comunidades étnicas o religiosas que, con armas u otros medios de destrucción, y organizados, provocan más de cien víctimas en un año a través de actos intencionados, sea cual sea su justificación (Fisas, 2004: 14).

Debido a las causales y complejidades del caso colombiano, el conflicto armado supera con creces la dinámica armada y todas sus manifestaciones y secuelas violentas. Sus laberintos tienen que ver con las violencias 
estructurales, culturales, políticas, sociales y simbólicas; con los intereses del poder local, regional y nacional tanto de los que lo detentan como de los que lo pretenden; con la democracia y sus exclusiones; con los partidos políticos; con los expropiadores de la tierra; y con la distribución de la riqueza en el país. Es por ello que la integralidad de toda esta complejidad social y política la englobamos como con el concepto de conflicto sociopolítico.

\section{LA VIOLENCIA ESTRUCTURAL}

De acuerdo al Informe sobre el Índice del Desarrollo Humano 2013. Elascenso del Sur: progreso humano en un mundo diverso, de Naciones Unidas emitido en el mes de marzo de 2013, Colombia ocupa el puesto 91 entre 186 países, lo que lo ubica entre los países con altos indicadores. Sin embargo, la desigualdad de los tres componentes de educación, vida larga y saludable, e ingresos, sigue polarizando a la población, cuestionando a la gobernabilidad y dificultando el desarrollo humano. La violencia de las estructuras socioeconómicas de Colombia se expresa en que un $50 \%$ de su población vive en pobreza severa, y entre un $20 \%$ y $30 \%$ es vulnerable a la pobreza.

La paradoja de clasificar a Colombia con índice alto, está en que a su vez los IDH del PNUD demuestran que el desarrollo rural no ha contribuido al bienestar de los pobladores del campo; no promueve el desarrollo humano y hace más vulnerable a la población rural; es inequitativo y no favorece la convergencia; es excluyente; no promueve la sostenibilidad ambiental; concentra la propiedad rural y crea condiciones para el surgimiento de conflictos; es poco democrático; no afianza la institucionalidad y las brechas entre la población urbana y rural se han profundizado (Informe Nacional de Índice de Desarrollo Humano, 2011, PNUD Colombia).

Esta violencia sistémica es producto de la explotación de la fuerza de trabajo, de la marginación económica y social, de la exclusión de población a los beneficios de la seguridad social, de la exclusión educativa, del desempleo estructural, de ineficientes políticas públicas de inclusión social, de corrupción e impunidad relacionados con el presupuesto nacional y los programas públicos de atención a la pobreza. Violencia estructural que coloca a la población en condición vulnerada y desechable por parte del sistema dominante. La inequidad de la distribución de la riqueza nacional expresa por una parte la inequidad social, y por otra la violencia que el sistema mantiene de manera 
estructural.

Uno de los nutrientes estructurales del conflicto sociopolítico en Colombia es la inequidad al acceso y la tenencia de la tierra. El Informe Nacional de Índice de Desarrollo Humano 2011, PNUD Colombia, demuestra que la estructura de la tenencia de la tierra es un obstáculo para el desarrollo humano. El monopolio de la concentración y tenencia de la tierra en manos de terratenientes, empresarios, transnacionales y actores armados ilegales, impiden que los campesinos, los indígenas y los afrocolombianos tengan tierra y disfruten de los territorios para el bienestar familiar, de manera que según el estudio del PNUD, "hay una relación inversa entre concentración de la tierra y desarrollo humano".

\section{LA VIOLENCIA DIRECTA}

Para entender la violencia directa del presente conflicto sociopolítico y económico en Colombia, señalaremos de manera extremadamente resumida tres períodos de la historia de los años recientes que nos permiten poner de relieve la paulatina y permanente confrontación entre el Estado y la subversión en Colombia con desastrosas consecuencias humanas para la población civil

- Estos mismos u otros periodos también deben ser estudiados desde la infaltable condición de paz, desde perspectivas que den cuenta no solo del conflicto armado sino también de sus contrapesos, de las convivencias, procesos y construcciones de paz que también están presentes en todo el acontecer social, económico, político y cultural de las regiones y del país.

\section{A) Primer Periodo: 1948-1953.}

Este primer período, que comenzó con el "bogotazo", estuvo marcado por el asesinato del carismático caudillo liberal Jorge Eliecer Gaitán. Lo más significativo fue el accionar de las masas y la personalidad del líder asesinado, en quien confluía una mezcla del radicalismo liberal con rasgos del populismo por entonces en boga, así como de un impreciso socialismo. Este acontecimiento generó la llamada "violencia en Colombia", que dejó un saldo superior a los 500.000 muertos. Este sangriento episodio fue causado por la pugna entre las dirigencias de los partidos oficiales liberal y conservador. De esto surgió un pacto político cuyo objetivo fue la pacificación del país, que recibió el nombre de "Frente Nacional" y consistió en la alternancia del poder entre el partido 
liberal y conservador durante 16 años (Alape, 983).

B) SEgUNDO PERIOdO: 1954-1965.

Se caracterizó por el surgimiento de diversos grupos alzados en armas y la aplicación de las llamadas "Repúblicas Independientes" dentro del país, controladas por el Bloque Guerrillero del Sur que posteriormente se convirtió en las Fuerzas Armadas Revolucionarias de Colombia (FARC). Este período ratifica el espíritu rebelde y combativo de sectores del campesinado, así como también la despiadada crueldad del gobierno para aplacar los brotes de rebelión. Por primera vez en la historia del país y de América, se utilizó lo más sofisticado de la técnica militar del momento: napalm, bombarderos, desplazamiento de equipo pesado y grandes contingentes de hombres, al igual que asesoría extranjera. Aniquilaron pueblos y aldeas campesinas sin discriminación de ningún tipo (Centro de Estudios Colombianos, 1983).

De 1957 a 1958 una junta militar de cinco generales asume el control del país, hasta que las élites políticas acordaron formar el Frente Nacional que les permitió el control alterno del partido liberal y conservador durante 16 años sin ninguna otra opción política.

\section{C) TERCER PERIODO: 1966-2013}

Este período ha estado caracterizado por el desarrollo de las más activas organizaciones guerrilleras que operan a nivel urbano y rural en todo el territorio nacional: Fuerzas Armadas Revolucionarias de Colombia (FARC), nacidas en 1963; Ejército de Liberación Nacional (E.L.N.), constituido en 1965; Ejército Popular de Liberación (E.P.L), organizado en 1967; Movimiento 19 de Abril (M-19), formado en 1970; Autodefensa Obrera (MAO), fundado en 1977; y el Destacamento Pedro León Arboleda (PLA), que irrumpe en el año de 1979. Las anteriores son sólo las organizaciones político-militares que en el período señalado tienen presencia a nivel nacional, por lo que no se incluyen los grupos de acción regional o local como el Movimiento Armado Indígena Quintín Lame.

Surgieron también dos significativos movimientos de masas que tuvieron presencia a nivel nacional y se enfrentaron de manera directa contra el Estado. El primero fue el FRENTE UNIDO, cuyo fundador e ideólogo fue el sacerdote y sociólogo Camilo Torres Restrepo, quien cayó en combate el 15 de febrero de 1966, poco después de haber ingresado al ELN. De este movimiento Frente Unido se desprendió el grupo GOLCONDA, que significó una ruptura con el ala jerárquica del clero. 
El segundo movimiento fue la Alianza Nacional Popular (ANAPO), creado y dirigido por el general Rojas Pinilla. De corte populista, alcanzó el triunfo electoral en 1970. Al ser usurpado mediante un gran fraude, una parte de este movimiento constituyó el Movimiento armado M-19.

Para el presente año 2013, las guerrillas que tienen existencia y accionar en varias partes de la geografía nacional son las FARC y el ELN. En lo militar, las guerrillas han sufrido golpes contundentes en los últimos cuatro años. A las FARC le han abatido varios de los miembros de su dirección nacional y mandos medios. La deserción de combatientes también ha aumentado, y sus otrora batallones, propios de una guerra regular, han involucionado a los frentes, escuadras y comandos móviles, característicos de una guerra de guerrillas. Sin embargo, en un reciente informe la Corporación Nuevo Arco Iris (2013) analiza el accionar de estas dos organizaciones guerrilleras y de los grupos neo-paramilitares llamados también bandas criminales, concluyendo que la geografía del conflicto armado se ha modificado con el desplazamiento de las acciones subversivas del centro a la periferia, manteniendo su intensidad bélica con ataques de alta precisión, atentados contra la infraestructura mineroenergética y la utilización de explosivos y minas antipersonales.

Según el estudio de Nuevo Arco Iris, el ELN hoy es una guerrilla más organizada y con mayor iniciativa que hace 12 años. En el año 2000 esta guerrilla contaba con 7.500 combatientes y dos años después, al inicio del gobierno de Álvaro Uribe, tenía cerca de 2.000 . Ha reducido su número de militantes armados y su área geográfica de influencia, pero sigue siendo una guerrilla fuerte con gran poder operativo.

El mismo estudio concluye que el nuevo paramilitarismo renace con la guerra entre el cártel de Medellín (los urabeños) y el cártel de Cali (los Rastrojos). Se pelean territorios, producción, procesamiento, distribución y comercialización de las drogas.

El escenario principal de todos los actores armados en Colombia (ejército nacional, guerrillas, para-militares y narcotraficantes) ha sido el campo, afectando negativamente y de manera directa al campesinado, a los pueblos indígenas y a las comunidades afrocolombianas a través de las amenazas, torturas, desapariciones forzadas, violaciones a mujeres, asesinatos selectivos y masivos, abandono y despojo de tierras, y desplazamiento forzado de sus hábitats.

La guerra de guerrillas en Colombia concentra su activar en la toma de pueblos, aniquilamiento de pequeñas unidades del ejército, destrucción 
de oleoductos, secuestros, destrucción de puestos de policía, retención de policías y militares, colocación de bombas, asesinatos selectivos de políticos, destrucción de caseríos y pueblos indígenas, combates a campo abierto, asesinato de dirigentes campesinos e indígenas, toma de carreteras, paros militares, quema de vehículos en vía pública, campos minados, cobro de impuestos, control territorial, social y comunitario.

Todos los actores armados legales e ilegales, han sido violadores de los derechos humanos y son responsables de crímenes de lesa humanidad como las desapariciones forzadas y las ejecuciones extrajudiciales no sólo contra sus adversarios sino también contra amplios sectores de la población civil que no tienen militancia política.

Toda esta parafernalia de violencias directas ha sido escrita, analizada, explicada e ilustrada de manera elocuente por sociólogos, historiadores, politólogos, antropólogos, psicólogos, filósofos, y literatos, todos ellos especializados en el arte de observar y describir la violencia convencional, la que mata, la que desangra, la que tortura, la que deshumaniza, la que viola, la que descuartiza, la que hace del ritual de la violencia y de sus simbolismos la construcción de la historia patria, o como lo recitan los marxistas: "la partera de la historia".

\section{VIOLENCIA CULTURAL}

La violencia estructural y la violencia directa se acompañan de la violencia cultural, es decir, de la violencia que se instaura como estilo de vida con manifestaciones implícitas y explícitas del poder. Tiende a conformar una cultura de la violencia como la dinámica del acontecer cotidiano donde la matriz subjetiva y la práctica se bifurcan a partir de la intolerancia política, religiosa, de género, del no reconocimiento y respeto a la diversidad, del no diálogo, y de la dominación total a través de la dominación, la subordinación, la sumisión, y la fuerza. En la cultura de la violencia los referentes simbólicos entran a formar parte del lenguaje, de las imágenes, de las consignas, de los íconos, y también de lo concreto.

La violencia cultural del Estado, de sectores de la sociedad y de actores armados, tiene sus máximas expresiones en: discriminación e invisibilización de género; la indiofobia; la exclusión y menosprecio a los afrocolombianos; la amenaza; la criminalización de la protesta social y de la política; el rechazo a la 
confrontación de ideas y de políticas; la intolerancia religiosa; la no aceptación de la diversidad étnica y cultural; la no aceptación de otras preferencias sexuales; el dogmatismo; el no respeto a otras identidades sociales, culturales, políticas, de género o religiosas.

A lo largo de los tres períodos surgieron, uno tras otro, los decretos, los artículos y demás engendros que restringen las libertades al cambiar de carácter la democracia burguesa y reprimir al máximo las movilizaciones y organizaciones populares. Mención especial en este sentido merece la aplicación de la figura jurídica del "estado de sitio". El artículo 121 de la Constitución colombiana le concede poderes autónomos al presidente para la defensa del Estado contra eventos de guerra exterior, grave conmoción interior o por perturbación del orden público, pudiendo instaurar el "estado de sitio". Este ha sido aplicado en varias ocasiones desde 1886, pero se implantó de manera continua desde el 9 de noviembre de 1949 hasta fines de la década del 80 el siglo pasado, es decir, más de 40 años bajo este régimen.

El estado de sitio o de excepción, implica la suspensión de las garantías individuales y de las libertades públicas, el poder descansa en la fuerza de las armas, pues el gobierno otorga la facultad ilimitada de represión a las fuerzas militares para que actúen bajo el imperio de la ley marcial. Las fronteras entre lo civil y lo militar se borran aceleradamente hasta llegar a la situación en que los militares gobiernan pero con la presencia de un presidente civil. Como consecuencia del estado de sitio, se asignó a la justicia penal militar el conocimiento de determinados delitos fundamentalmente políticos y el juicio de los civiles por parte de los tribunales castrences (Consejos de guerra, Tribunal Superior).

Paralelamente a ello se coartaron, también a través de decretos, los derechos políticos y las garantías sociales más elementales de los colombianos: se impidió la libertad de reunión, de expresión, de información, se erigieron en delitos conductas meramente reivindicativas de los sectores populares, se extendió la facultad de la policía judicial a los servicios de inteligencia militar, se generalizó la tortura, la detención arbitraria y las desapariciones de miles de colombianos. Se ejerció el régimen del terror en las cárceles del país, se crearon y consolidaron campos de concentración y se conformaron más de ciento cincuenta organismos para-militares (los escuadrones de la muerte). Hechos cotidianos con los allanamientos, las detenciones y el amedrentamiento a familiares y amigos de personas vinculadas con los revolucionarios. Toda esta situación represiva generalizada ha obligado a un gran número de colombianos 
al desplazamiento interno o al exilio en otros países como única posibilidad de poder esquivar la represión y salvar sus vidas.

En 1980 la organización Amnisty International visitó Colombia y realizó un informe sobre la violación de los derechos humanos con "...pruebas convincentes de que las fuerzas armadas han adoptado una política de terror para intimidar y eliminar a la oposición... sectores enteros de la sociedad corren el riesgo de ser considerados subversivos, lo que en Colombia equivale a una sentencia de muerte" (Amnisty International, 1984).

Todas las violencias anotadas sin duda son un buen caldo de cultivo para reproducir la violencia armada directa. Viene al caso un estudio realizado por Rachel Brett e Irma Specht publicado por la OIT con el sugestivo título de Jóvenes, soldados y combatientes ¿por qué van a luchar? Este libro congrega la visión de los niños y expone múltiples razones por las que se vinculan a la guerra, entre otras dice que:

La adolescencia es una época de vulnerabilidad, con las incertidumbres y las turbulencias del desarrollo físico, mental y emocional. Es también el tiempo de las oportunidades de una libertad mayor, del desarrollo de la comprensión de la propia identidad y del lugar en la comunidad y en la sociedad, y de una nueva capacidad para hacer escogencias y asumir responsabilidades. La etapa de la pubertad, durante la cual muchos de estos jóvenes se enrolaron, se caracteriza por sentimientos de oposición y resistencia a la autoridad y a las estructuras de poder en las familias, la escuela y el Estado. Además, es un tiempo en el que la injusticia y su inaceptabilidad se sienten fuertemente. Las razones por las que los jóvenes se enrolan en las fuerzas armadas y los grupos armados reflejan todos estos aspectos de esta etapa específica de la vida (OIT, 2005: 18).

Un rápido ejemplo de combinación de todas las violencias, con acentuación en la violencia cultural, es el que sufren los pueblos indígenas. "En lo particular, las acciones de los violentos y la aplicación del Plan Colombia en sus territorios no les permite a los indígenas ejercer la autonomía territorial y regional, nombrar a sus autoridades, disentir de todos los violentos del Estado y de los que se oponen a éste, y tener el más elemental de los derechos: la vida" (Sandoval, 2008:32).

Toda esta actuación de los violentos del Estado y de los grupos armados ilegales en los territorios indígenas, confluyen en un etnocidio de estos pueblos a través de la destrucción de sus comunidades, sus costumbres, sus organizaciones, su cultura, su base económica, su entramado y sus organizaciones sociales tradicionales. Los persiguen, les asesinan dirigentes, 
les expropian sus tierras, sus territorios son escenarios de guerra, sus mujeres violadas, y son obligados al desplazamiento interno. De acuerdo al informe del Centro de Monitoreo de Desplazados Internos (CMDI), emitido el 29 de abril de 2013 en Ginebra, Colombia tiene la mayor cantidad de desplazados internos en el mundo, con al menos cuatro millones 900 mil personas, seguida por Siria, con dos millones 400 mil, de un total mundial de 28,8 millones en 2012. Por su parte, la Consultoría para los Derechos Humanos y el Desplazamiento (CODHES) ha registrado un total de cinco millones 200 mil personas en desplazamiento forzado interno a partir del año 1985.

\section{LAS NEGOCIACIONES Y LOS ACUERDOS}

En ese devenir de las confrontaciones violentas, varios han sido los diálogos directos o con mediación, entre la insurgencia y el Estado. En la literatura académica colombiana existe un número bastante amplio de trabajos que describen y analizan las negociaciones entre el gobierno y la insurgencia armada, generalmente denominados "negociaciones de paz", "acuerdos humanitarios", "cese al fuego", o "acuerdos de paz"1

A manera de ejemplo, recordamos que en la década del cincuenta del siglo pasado las guerrillas del Llano tuvieron negociaciones con el gobierno. En 1984 se firmaron acuerdos de cese al fuego, tregua y diálogo nacional. En 1990, se desmovilizaron y entregaron las armas el grupo $\mathrm{M}-19$, el Movimiento Indígena Quintín Lame, frentes armados del EPL y del ELN, y se elaboró una nueva Constitución. Esta Carta Magna es una de las más avanzadas en América Latina en el reconocimiento multicultural del país y de los derechos colectivos de los pueblos indígenas, teniendo como ejes rectores la justicia social, la libertad, la inclusión y la democracia.

Años después en las negociaciones con las FARC en 1998, el gobierno mediante decreto presidencial le despeja a la guerrilla más de 42 mil kilómetros cuadrados en los departamentos del Meta y Caquetá en el sur de Colombia, para discutir una agenda de 12 puntos relacionados con la democracia, el problema agrario, la justicia social, los derechos humanos y las reformas al Estado. En el año 2000, los Estados Unidos implementan el "Plan Colombia" con una ayuda inicial de más de 860 millones de dólares destinados principalmente a las

\footnotetext{
${ }^{1}$ Un importante estado del arte sobre negociaciones en Colombia las encontramos en Alderid Gutiérrez Loaiza (2012).
} 
fuerzas armadas para la lucha contra el narcotráfico, que después se extiende contra las guerrillas. El apoyo creciente y directo de Estados Unidos mediante la ayuda militar, convierten a Colombia en el segundo país del mundo con mayor recepción militar y, por supuesto, con su correspondiente crisis humanitaria ${ }^{2}$. El proceso de negociación terminó en el año 2000, se cancelan las negociaciones y el despeje del Caguán, y se intensifica otra vez la confrontación militar.

Por otra parte, el gobierno concretó un proceso de desmovilización de varias organizaciones paramilitares en los años 2006-2007. Según la estadística oficial, para febrero del año 2012 sumaron un total de 35,407 para-militares desmovilizados $^{3}$. Sin embargo, a pesar de este proceso importante de desmovilización de grupos violentos, y según el Informe de Indepaz, por lo menos

271 municipios del país tienen presencia continua de grupos paramilitares con un activo de 8 a 9 mil integrantes ${ }^{4}$.

El 18 de octubre de 2012 iniciaron formalmente negociaciones la guerrilla de las FARC y el gobierno colombiano, con el auspicio de la diplomacia noruega y cubana. Los delegados del Gobierno de Colombia y las Fuerzas Armadas Revolucionarias de Colombia-Ejército del Pueblo (FARC-EP) establecieron un "Acuerdo general para la terminación del conflicto y la construcción de una paz estable y duradera".

En el acuerdo declaran las dos partes que:

"Atendiendo el clamor de la población por la paz, y reconociendo que:

- La construcción de la paz es asunto de la sociedad en su conjunto que requiere de la participación de todos, sin distinción, incluidas otras organizaciones guerrilleras a las que invitamos a unirse a este propósito;

- El respeto de los derechos humanos en todos los confines del territorio nacional, es un fin del Estado que debe promoverse;

- El desarrollo económico con justicia social y en armonía con el

\footnotetext{
${ }^{2}$ Según el Informe 2006 de la Comisión Colombiana de Juristas, el 75\% de los delitos de lesa humanidad cometidos en los últimos 4 años han sido responsabilidad del Estado colombiano.(http://www.coljuristas. org/documentos/documentos_pag/SituacionDDHH 2006).

${ }^{3}$ Datos del Grupo de Atención Humanitaria al Desmovilizado (GAHD) y Oficina del Alto Comisionado para la Paz (OACP). http://www.observatorioddr.unal.edu.co/cifrasDDR.html

${ }^{4}$ Sobre las cifras oficiales. Juan Carlos Jiménez. Indepaz http://www.indepaz.org.co/wp-content/ uploads/2012/05/Sobre-las-cifras-oficiales.pdf
} 
medio ambiente, es garantía de paz y progreso;

- El desarrollo social con equidad y bienestar, incluyendo las grandes mayorías, permite crecer como país;

- Una Colombia en paz jugará un papel activo y soberano en la paz y el desarrollo regional y mundial;

- Es importante ampliar la democracia como condición para lograr bases sólidas de la paz;

Con la disposición total del Gobierno Nacional y de las FARC-EP de llegar a un acuerdo, y la invitación a toda la sociedad colombiana, así como a los organismos de integración regional y a la comunidad internacional, a acompañar este proceso".

En el acuerdo entre el Gobierno de Colombia y las FARC se estableció una agenda de negociación muy parecida a los "Acuerdos de Paz" firmados entre el gobierno de El salvador y el Frente Farabundo Martí para la Liberación Nacional (FMLN) en el castillo de Chapultepec en México el 16 de enero de 1992, después de doce años de guerra entre la subversión y el Estado. De igual manera, la agenda de Colombia es muy similar a "Los acuerdos de Paz" signados por el Estado/Ejército y la Unidad Revolucionaria Nacional Guatemalteca (URNG) el 26 de noviembre de 1996 después de 30 años de confrontación militar, con el propósito de dar "Una solución política al enfrentamiento armado... para superar las causas de dicho enfrentamiento y sentar las bases de un nuevo desarrollo". El lema de los acuerdos fue "La paz firme y duradera", y a 17 años de su firma y desmovilización del ejército revolucionario, el desarrollo prometido no ha llegado y los acuerdos no se han cumplido.

Cinco son los grandes temas que integran la agenda de negociación que adelantan en la Habana el gobierno y las FARC:

1. Política de desarrollo agrario integral

2. Participación política

3. Fin del conflicto

4. Solución al problema de las drogas ilícitas

5. Víctimas 


\section{Implementación, verificación y refrendación}

El modelo de negociación por lo pronto ha tenido tres características: a). Negocian fuera de Colombia, en la Habana, en un país diferente al escenario de la confrontación. B). Negocian sin cese al fuego, en medio del conflicto y con una intensidad militar por parte del Ejército Nacional y también de las FARC. C). El tipo de negociación es bilateral, y d). Los acuerdos no son públicos en tanto no concluya toda la negociación.

Llegar a sentarse en la misma mesa el gobierno y las FARC para dialogar y establecer acuerdos, de entrada implica la aceptación del gobierno de un conflicto social y político en el país, así como el reconocimiento tácito de las FARC como una entidad política. Para las FARC implica reconocer que la guerra no tiene futuro y que la negociación política es la salida más civilizada al conflicto en Colombia.

El 16 de mayo de 2013, los delegados de las FARC-EP y el Gobierno de Colombia, informaron haber llegado a un acuerdo sobre el primer punto de la Agenda contenida en el "Acuerdo General para la terminación del conflicto y la construcción de una paz estable y duradera". El acuerdo lo llamaron "Hacia un nuevo campo colombiano: Reforma rural integral" y los temas convenidos fueron:

- Acceso y uso de la tierra. Tierras improductivas. Formalización de la propiedad. Frontera agrícola y protección de zonas de reserva.

- Programas de desarrollo con enfoque territorial.

- Infraestructura y adecuación de tierras.

- Desarrollo social: salud, educación, vivienda, erradicación de la pobreza.

- Estímulo a la producción agropecuaria y a la economía solidaria y cooperativa. Asistencia técnica. Subsidios. Créditos. Generación de ingresos. Mercadeo. Formalización laboral.

- Políticas alimentarias y nutricionales.

El comunicado explicita que el acuerdo tiene que ver con transformaciones "de la realidad rural y agraria de Colombia con equidad y democracia. 
Está centrado en la gente, el pequeño productor, el acceso y distribución de tierras, la lucha contra la pobreza, el estímulo a la producción agropecuaria y la reactivación de la economía del campo" a través de la creación de un Fondo de Tierras para la Paz. El acuerdo plantea "un campo con protección social, erradicar el hambre a través de un sistema de alimentación y nutrición" así como restituir a las víctimas del despojo y del desplazamiento forzado.

El contenido del acuerdo tiene de fondo dos componentes importantes que no habían sido precisados con tanto detalle en negociaciones anteriores. El primero es el de revertir una condición histórica de estructura violenta en el campo colombiano, y segundo, la justicia social. Los dos componentes se circunscriben dentro del concepto de paz positiva, y queda solo esperar a que el tiempo y la situación demuestren su operatividad. Recordemos por lo pronto dos variables determinantes para que se concrete o para que quede en los recuerdos de las buenas intenciones: el principio de las conversaciones entre el Gobierno y las FARC-EP es que "nada está acordado hasta que todo esté acordado", es decir que los acuerdos solo serán posibles de instrumentarse hasta que lleguen a un acuerdo de la totalidad de la agenda. La segunda variable tiene que ver con todos los enemigos de la paz: grupos armados, algunos políticos, algunos terratenientes, el narcotráfico, delincuencia común, los expropiadores de tierras, expresidentes de Colombia (Álvaro Uribe y Misael Pastrana)

\section{LA CONSTRUCCIÓN DE LA PAZ EN COLOMBIA}

Destrabar un conflicto militar tan complejo como el colombiano, requiere también una complejidad en la negociación, en la política, lo social, lo informativo, y lo económico. Una guerra que tiene varios actores armados y con ello muchos intereses económicos y de poder, ha hecho que en este país sectores amplios de la población y de la clase política, tengan como modus vivendila violencia y las drogas. La narco-política, otro de los flagelos y de las variables en el conflicto en Colombia, continúa su existencia a pesar de los más de cincuenta miembros del Congreso de la República procesados por ese delito (la para-política). Sin duda otro ingrediente de gran magnitud es el que tiene que ver con la venta y compra de miles de armas, municiones, pertrechos y demás componentes de toda logística para la guerra, la cual procede de los 
países productores y comercializadores de armas. Por toda esta complejidad es que la paz tiene muchos enemigos internos y externos que de manera persistente, y desde todos los ámbitos políticos, jurídicos y sociales, ponen obstáculos para impedir que se acabe la violencia directa.

Independientemente del rumbo que tomen las negociaciones, varias son las maneras de comprender la realidad de las violencias y la construcción de las paces en este país. Por supuesto que desde cualquier mirada de paz será siempre bienvenida la negociación, los acuerdos, los diálogos, la mediación, la desmovilización, el silencio del rugir de las armas, la transformación noviolenta de los conflictos, y la metamorfosis de las agrupaciones armadas en organizaciones, movimientos o partidos políticos en escenarios legales.

En la perspectiva de la paz negativa (Galtung 1985), un país en paz es aquel que no tiene violencia directa, hay ausencia de guerra, y por ello se busca vencer al enemigo a las buenas o a las malas. El gobierno colombiano busca la paz negativa, el presidente Juan Manuel Santos lo ha dicho: que con acuerdo o sin él, las FARC tienen que ser derrotadas. Se pretende una victoria militar, política y diplomática que permita la continuidad del sistema político actual, y por ello intensifican las acciones de guerra paralelas a la negociación con la guerrilla. En esta tesitura, la derrota militar de la guerrilla o la desmovilización pactada, en nada o en poco afectarán la violencia estructural del sistema capitalista, y no impide que se hable, se escriba y se incremente la oratoria de la paz, su utilización política y su folclorización. Para esta paz negativa no se requiere de la participación de la sociedad civil, al contrario, su presencia e intervención dificulta los posibles acuerdos del gobierno y la guerrilla.

Hemos sostenido que en Colombia hay una violencia estructural sistémica exasperante contra la mayoría de la población; la acompaña una violencia cultural y otra violencia directa, que hacen que la condición socio-económica sea una de las más desiguales e injustas del mundo, en un país inundado de riquezas naturales y medioambientales. Frente a esta violencia integral, se requiere trabajar en dirección de una paz integral, que revierta las causas generadoras de la injusticia social, económica, de la falta de libertad, y de democracia.

Algunos actores decidieron luchar contra esas violencias a través de las armas, y la respuesta del Estado también ha sido violenta, generándose una espiral de violencias crecientes que han hecho de Colombia un país victimizado por la guerra y un régimen político incapaz de garantizar la denominada paz 
social. Otros, la mayoría del pueblo colombiano, han decidido el camino de la lucha pacífica activa noviolenta en todos los contextos de la vida nacional. Un ejemplo que nos permite aquilatar la comprensión del accionar armado por un lado, y por otro de la aprehensión de los habitus de la paz, se encuentra referido en una carta enviada el 16 de mayo de 2013 al máximo comandante de las FARC por parte de los líderes indígenas de la Organización Nacional Indígena de Colombia (ONIC), del Consejo Regional del Indígena del Cauca (CRIC), y la Asociación de Cabildos Indígenas del Norte del Cauca (ACIN), donde le dicen:

La guerrilla tendrá sus razones de existir, sus objetivos o planes. Tendrán razones para haber optado por una lucha armada. Nosotros en el Cauca tenemos nuestras razones para haber optado por una lucha pacífica. Por eso no estamos en contra de los diálogos. Al contrario, los felicitamos y saludamos. Porque creemos que ese es el camino. Lo que no podemos aceptar es que mientras se dialoga, se sigan cometiendo faltas gravísimas en nuestro territorio. Nosotros no estamos castigando el proceso de paz. Estamos castigando las faltas en nuestro territorio (ACIN, 2013).

La paz que han venido ideando y en buena medida construyendo los indígenas, se enmarca en la paz integral, en aquella que se edifica con el ejercicio de derechos económicos, sociales, políticos, y culturales, asociados estos derechos a la justicia social, a la equidad, a la democracia social, la libertad, y de manera particular a la autonomía y autodeterminación indígenas.

Para llegar a la condición de paz integral, se requiere avanzar en pequeños pasos en ciertos procesos, y en otros a marchas forzadas. Una negociación del conflicto armado es un pequeño paso, sin duda muy importante y necesario para llegar a condiciones de paz negativa, es decir, de una paz donde existen todas las demás violencias, excepto la violencia armada directa. La negociación del conflicto armado por sí misma no conduce a la paz social, ni mucho menos a la paz integral, pero sí mejora condiciones de vivencia de la población y posibilita irrumpir en los otros ámbitos con miras a construir una paz lo menos imperfecta posible. No cabe duda que si a todas las violencias que sufre un pueblo le quitamos la violencia directa, mejoran las condiciones de vida material, social y psicológica de manera importante - por supuesto que en condiciones de paz aún imperfectas-, lo que facilita con creces avanzar por los caminos de las paces posibles.

Si revisamos la agenda y los diálogos del gobierno y las FARC-EP, no hay ningún punto a discutir sobre las causas violentas estructurales del modelo económico basado en la súper-explotación del capital nacional y transnacional, ni tampoco de la concentración de la propiedad de la tierra en unos cuantos 
terratenientes. Sobre ello el gobierno ha sido muy enfático al declarar que el modelo económico y político no está en discusión, por lo que la negociación se dirige más bien a la potencial posibilidad de incorporar campesinos y adaptarlos al modelo neoliberal agrario, quedando intactas las estructuras históricoestructurales dominantes de concentración de la tierra y de la riqueza. Con ello la paz negativa se afianza; y la paz social seguirá en espera.

Con todo lo que implica una paz negativa, y sin ser conformistas, la firma de los acuerdos, cumplidos o no, dan un gran respiro a una población azotada hace más de sesenta años por un ininterrumpido baño de sangre. Además, se requiere también que los otros actores armados dejen de serlo y se integren a la vida política y social del país. El dilema inmediato está en la firma de un acuerdo con cambios sociales y políticos que desmovilice actores armados y evite nuevos ciclos de violencia en Colombia, pues sin duda que es menos dolorosa, agobiante- y destructora la situación sin violencia que con ella.

Los pasos siguientes serán más complejos en el pos-conflicto, que tiene entre uno de sus objetivos más complejos el de desarmar las mentes de los que hicieron de su modus viviendiy de sus vidas la cultura de la violencia, para edificar una cultura para la paz. Es decir, que el proceso tiene que trascender del desarme y la desmovilización a la reintegración social a través de políticas públicas para la paz que posibiliten la reconfiguración de nuevos proyectos de vida en ámbitos familiares, sociales, laborales y educativos en perspectivas de paz.

La primera fase de la transformación pacífica del conflicto armado en Colombia viene siendo una paz negativa, necesaria pero insuficiente, pues las experiencias de Guatemala y El Salvador son aleccionadoras en cuanto a que la no trascendencia a una paz positiva y más particularmente a una paz integral con justicia, libertad y democracia, agrava las condiciones de violencia por parte de la delincuencia común. El mismo caso de Colombia con las desmovilizaciones de la década del noventa del siglo pasado y las de la década del diez del presente siglo, han demostrado que la desmovilización y el desarme de grupos violentos de derecha o izquierda han sido en buena medida la base y dirigencia de los actuales grupos criminales de delincuencia común. ¿Cómo reinsertar positivamente y educar en la cultura para la paz a más de 9 mil combatientes de las FARC y quizás cerca de medio millón de milicianos, simpatizantes y colaboradores que han aprehendido la cultura de la violencia que incluye el poder y el manejo de cantidades importantes de dinero sin trabajar?

Pensar y actuar en sentido de paz positiva implica revertir las condiciones 
estructurales de la violencia en Colombia, al igual que la eliminación de la violencia armada directa, es decir de la desmovilización y desintegración de todas las organizaciones armadas no legales. En concreto es no solamente la negociación, los acuerdos y los pactos para el silenciamiento de las armas, sino también el cuestionamiento y el cambio del modelo neoliberal impuesto en el país. Frente a este segundo aspecto, el Estado y el gobierno en Colombia han sido explícitos en manifestar que el sistema político y económico no lo negocian.

Sin embargo, algunos aspectos de reformas económicas y políticas dentro del mismo sistema neoliberal, son parte de la negociación. Entre ellas el derecho a la alimentación; la erradicación del hambre y la desnutrición; el ordenamiento espacial y territorial que garantice las Zonas de Producción Campesina de Alimentos y las Zonas de Reserva Campesina, así como los territorios indígenas y afrodescendientes; y la provisión de infraestructura física para la producción, la comercialización y el acceso a los mercados.

En esta perspectiva de paz positiva también se discute y se pretende concretar derechos básicos de la población en sentido humanitario, social y político. Esta configuración de paz positiva tiene tres posibilidades en cuanto a sus participantes. Puede llegar a acordarse entre los negociadores del conflicto, el gobierno y las FARC. Puede llegar a tener alguna participación de la sociedad sin estar presente de manera directa en la mesa de negociación y acuerdos. Tercera, la sociedad, o el pueblo como otros dicen, participa activa y directamente en los acuerdos y en la construcción de la paz positiva.

En este contexto de violencias, innumerables han sido los pensares, los haceres y los habitus de paz negativa, positiva e imperfecta. Indígenas, campesinos, obreros, intelectuales, artistas, religiosos, comunidades, políticos, organizaciones sociales y sectores del gobierno han empeñado sus esfuerzos, su trabajo y sus vidas en la construcción de las paces en Colombia. Experiencias inéditas son las de la Asamblea por la Paz, la Red de Universidades por la Paz, Mujeres por la Paz, la Ruta social común para la paz, La Red contra el hambre y la Pobreza, el Congreso para la Paz, la Comunidad de Paz de San José de Apartado, la Red de Comunidades por la Paz, la Red de Iniciativas por la Paz (Redepaz), la Diplomacia Ciudadana por la Paz, y el Congreso de los Pueblos. Con visiones convergentes y divergentes sobre la construcción de la paz, estos movimientos sociales por la paz han manifestado en foros, marchas, asambleas y congresos, que la negociación del conflicto armado es imprescindible pero no es la paz social. Reivindican su necesaria y obligatoria participación para los 
acuerdos y la construcción de la Paz que transforme las causas estructurales violentas predominantes en Colombia. Dicen los indígenas nasa del Cauca:

Sabemos que la dejación de la armas no es por ningún motivo paz. La guerra sigue. Frente a todas las estrategias planteadas por el gobierno como el fuero penal militar, el plan de consolidación territorial, las locomotoras del desarrollo, la privatización de los recursos naturales y los servicios y la destrucción de la Madre Tierra. Los pueblos que buscamos y estamos en una construcción de la paz, debemos estar preparados para las consecuencias de estas negociaciones. El llamado pos-conflicto es inminente (La Paz del modelo y el Congreso para la Paz, 2013:1).

Por su parte, el Congreso para la Paz, que se reunió en Bogotá en mayo de 2013 con cerca de 20.000 personas para mandatar en torno a una agenda, y el movimiento social; que requiere el país para encontrar una solución definitiva al conflicto social, político y armado, declaró:

Seguimos sosteniendo que la paz no consiste únicamente en el silenciamiento de los fusiles. A nuestro juicio, no podrá consolidarse una sociedad en paz sin los cambios necesarios que ataquen de manera decidida las raíces del conflicto y sin revertir las acciones del Estado que vulneran los derechos de los pueblos. Las graves problemáticas que vive la mayoría del pueblo colombiano son factores que profundizan el conflicto, por esa razón avanzamos en delinear una agenda social de paz planteada en perspectiva de superar las condiciones de pobreza, desigualdad, marginalidad, impunidad y exclusión política que han caracterizado al régimen político imperante, a través de la lucha organizada. Esa agenda social de paz es expresión de los anhelos de las comunidades, pueblos y organizaciones sociales que buscan una sociedad con una paz genuina basada en la plena garantía de los derechos humanos y la construcción de un país más equitativo

Todas las organizaciones y movimientos por la paz proponen una agenda de paz desde la sociedad civil, se plantean ser actores activos y participativos para la paz, y en su generalidad vienen discutiendo temas como: Mujeres por la Paz, Educación y Paz, Tierra y Territorio para la Paz, Trabajadores y Sindicalismo por la Paz, Juventud por la Paz, Derechos Humanos, Militarización de Colombia y planes de vida para un buen vivir. El Congreso para la Paz se propone "La construcción del movimiento social por la paz persiguiendo una gran confluencia democrática y popular por la paz y los cambios", es decir, que se propone la construcción de una paz participativa e incluyente de todos los sectores sociales en Colombia, que transformen no solo la violencia directa sino de manera importante la violencia estructural y la cultural. 
"Cuenten con nosotros para la paz. No nos cuenten para la guerra", en reiteradas ocasiones le han dicho los indígenas a las guerrillas y al Estado en Colombia. Los que sufren las más lacerantes violencias y a los que les han asesinado y desplazado centenares de personas y familias de sus tierras y territorios.

La "Oración por la Paz", escrita por el poeta, novelista y ensayista colombiano, William Ospina, y leída por la ex senadora Piedad Córdoba en la Plaza de Bolívar en el acto central de la Movilización por la Paz y la Democracia el día 9 de abril de 2013, es otra de las declaraciones más elocuentes de la contribución e inclusión en el proceso de construcción de paz: "Ahora comprendemos que un pueblo no puede sentarse a esperar que llegue la paz, que es necesario sembrar paz para que la paz florezca, que la paz es mucho más que una palabra (Ospina, en oración por la Paz, 2013)".

Esta lucha por la construcción de una paz integral con justicia, libertad y democracia, hace referencia a que es un proceso siempre en de-construcción, construcción y re-construcción de la paz en todas las dimensiones, por lo que es en sí mismo un proceso y una dinámica inacabados en tiempos y espacios contextuales que se presentan con altibajos de tipos de paz y de conflictos, esto hace referencia al concepto de "paz imperfecta" (Muñoz, 2004), de un constructo complejo de la convivencia humana.

\section{ANOTACIÓN FINAL}

Desde hace más de sesenta años las violencias y las paces han estado presentes en los diferentes periodos de la historia de Colombia. En algunos ha tenido presencia y mayor activación la violencia directa armada que la violencia estructural sistémica y que la violencia cultural. La dualidad paz y guerra ha sido permanente en la historia del país, pero de manera incuestionable han sido más dominantes las condiciones y convivencias pacíficas que las violentas, mismas que alteran en periodos, tiempos y contextos la coexistencia apacible de una población que mayoritariamente piensa y le apuesta a la paz.

La violencia estructural que se manifiesta de manera explícita en la miseria, la desigualdad, la pobreza, la indigencia, la exclusión y la marginación de importantes sectores de la población, así como la violencia cultural y simbólica concretada en la indiofobia y la discriminación a los afrodescendientes y mujeres, han sido dos de los factores causales determinantes de la violencia 
directa armada.

La desigualdad, la marginación, los altos niveles de exclusión, la extrema pobreza y riqueza, la concentración del poder económico y político, y la falta de oportunidades laborales y educativas, se han acompañado de una intensidad de represión estatal y para-estatal. Esta violencia estructural, propia del sistema político capitalista, en su transcurrir no ha contado con lo que suele denominarse "voluntad política" por parte del Estado y los gobiernos para revertir las causas estructurales de la pobreza, generándose miseria intergeneracional.

Los costos sociales, humanos y ambientales de la guerra se pueden resumir en el drama de carácter nacional de la violación a los derechos humanos, sociales, culturales y políticos de la sociedad en general, y del no respeto a los derechos colectivos de los pueblos indígenas.

El conflicto sociopolítico y económico armado en Colombia es uno de los factores determinantes que impide un mayor desarrollo humano, social, político, cultural y económico del país. El conflicto armado y el desplazamiento forzado (una de sus secuelas), inciden negativamente en la desintegración familiar, social, comunitaria y nacional. Todos los actores armados, incluyendo al ejército nacional, son responsables de todas las consecuencias de la guerra, así como de los crímenes de lesa humanidad cometidos contra la población civil, pero con mayor afectación contra los campesinos, las muyeres rurales y los pueblos afrocolombianos.

En medio de esa multiplicidad de violencias, los intelectuales, campesinos, indígenas, obreros, estudiantes, profesores universitarios, organizaciones civiles, comunidades, líderes comunitarios, religiosos y pueblo en general, vienen construyendo diversos pensares y experiencias de paces en contextos comunitarios, regionales y nacionales. Esas paces han estado referenciadas a la paz negativa, a la paz positiva, a la paz imperfecta, y a la paz integral con justicia, libertad y democracia. En todas sus expresiones, reclaman una solución política al conflicto armado en Colombia y una participación activa y directa en la construcción de la paz, pues como dicen los indígenas nasa "El fin del conflicto armado no es la paz. Construirla exige aprender a oír a los sectores más vulnerables y contar con un Estado capaz de proteger eficazmente sus derechos. Esto es particularmente urgente con las minorías étnicas" (CRIC, 2013).

Ello también deviene de las experiencias de transformación pacífica de conflictos armados que se registran después de la Segunda Guerra Mundial, pues a pesar de las enormes dificultades que se presentan en las negociaciones 
y los acuerdos, es el camino más indicado para cimentar las bases de una sociedad de convivencia pacífica en todas sus dimensiones.

\section{BIBLIOGRAFÍA}

Alape, Arturo (1983) El Bogotazo: memorias del olvido. Casa de las Américas, Cuba.

Alderid Gutiérrez Loaiza (2012). Negociaciones de paz en Colombia, 19822009. Un estado del arte. Estudios políticos, 40. Instituto de Estudios Políticos, Universidad de Antioquia, pp. 175-200.

Amnisty International (1984) Una crisis de derechos humanos. Edit. EDDI, España.

Departamento Administrativo Nacional de Estadísticas (DANE 2005)

http://www.colombiestad.gov.co

Asociación de Cabildos Indígenas del Norte del Cauca (2013). La Paz del modelo y el Congreso para la Paz. http://www.nasaacin.org/.

Consejo Regional Indígena del Cauca (2013). Pensamiento Indígenas a la Carta Social Andina del Parlamento Andino, en: http://www.cric-colombia. org/portal/pensamiento-indigenas-a-la-carta-social-andina-del-parlamentoandino/

Brett, Rachel e Irma Specht (2005). Jóvenes, soldados y combatientes ¿por qué van a luchar?, OIT, Dupligráficas Ltda., Colombia.

Corporación Nuevo Arco (2013).

http://www.arcoiris.com.co/category/a-profundidad/informes/

Fisas Vicenc (2004). Procesos de paz y negociación en conflictos armados. Barcelona, Paidós ibérica.

Galtung, Johan (1985). Sobre la paz. Barcelona: Fontamara.

Galtung, Johan (1995). Investigaciones Teóricas. Madrid: Tecnos

Muñoz, F. (2001). La Paz Imperfecta. Granada: Universidad de Granada.

Muñoz, F. (2004). "La paz". En B. Molina y F. Muñoz (coords.), Manual de Paz y Conflictos. Granada: Universidad de Granada, 21-42.

Muñoz, Francisco A. y Jorge Bolaños Carmona (Ed.) (2011). Los Habitus de la Paz. Teoría y práctica de la paz imperfecta. Granada: Instituto de la Paz y los 
Conflictos.

PNUD (2013). Informe sobre el Índice del Desarrollo Humano 2013. El ascenso de/ Sur: progreso humano en un mundo diverso, Naciones Unidas.

Sandoval Forero, Eduardo Andrés (2008). La Guardia Indígena Nasa y el Arte de la Resistencia Pacifica. Ediciones Colección Étnica, Hemera, Colombia.

Eduardo Andrés Sandoval Forero esaforero2002@yahoo.com

Antropólogo y Doctor en Sociología con Estancia pos-doctoral en Diversidad Cultural, Democracia y Paz, en el Instituto de la Paz y los Conflictos, Universidad de Granada, España. Fundador y actual coordinador Académico Honorario de la Maestría y Doctorado en Estudios para la Paz, la Interculturalidad y la Democracia en la Universidad Autónoma Indígena de México (2011-2014). Integrante del Grupo de investigación Internacional "Paz Imperfecta y Conflictividad". Investigador Nacional nivel II del Consejo Nacional de Ciencia y Tecnología -desde 1995- (CONACYT), México. Profesor-investigador del CIEAPUAEMex. Miembro del Comité Ejecutivo de la Asociación Latinoamericana de Sociología (ALAS). Publicación reciente: Educaciones Interculturales en México (2013), Estudios Sociológicos Editora. Coordinador del Seminario Internacional en Resolución de Conflictos y Construcción de Paz, Consorcio de Universidades Cátedra UNESCO- UAIM. 